\title{
MÍDIA E SAÚDE: CONEXÕES, PRODUÇÕES E (IN)VISIBILIDADES
} COTIDIANAS

\section{Kátia LERNER ${ }^{1}$ e Isaltina GOMES ${ }^{2}$}

O bem-estar físico, os processos de adoecimento e as formas de conceber a ação terapêutica sempre foram questões importantes para diversas sociedades, mas que assumiram sentidos distintos conforme contextos históricos e socioculturais específicos. A emergência da concepção moderna ocidental de saúde se caracterizou pela ascensão do poder biomédico e sua progressiva preponderância sobre os demais discursos. Foucault ressalta as novas relações entre saber e poder que se estabeleceram a partir do século XIX, nas quais a concepção de saúde tornou-se vinculada a um projeto de nação e à ideia de civilização, onde cabia ao Estado agir sobre o espaço público, regular os corpos e curar.

Com o desenvolvimento dos conhecimentos e tecnologias médicas e a disseminação de suas racionalidades, um novo momento de inflexão se deu no século XX. Observa-se uma mudança no padrão epidemiológico, com a diminuição das doenças transmissíveis e a emergência das enfermidades crônico-degenerativas como principal causa de morte. Esse

\footnotetext{
${ }^{1}$ Kátia Lerner é pesquisadora da Fundação Oswaldo Cruz e professora permanente do Programa de Pósgraduação em Informação e Comunicação em Saúde. Realizou pós-doutorado em Comunicação e Cultura na Escola de Comunicação da UFRJ, doutorado em Sociologia e Antropologia na UFRJ, com doutorado sanduíche na UCLA, e mestrado em Comunicação e Cultura na ECO/UFRJ. É autora do livro Memórias da dor: coleções e narrativas do Holocausto (Brasília: IBRAM, 2013) e organizou, junto com Igor Sacramento, a coletânea Saúde e Jornalismo: interfaces contemporâneas (Rio de Janeiro: Ed. Fiocruz, 2014). É Vice-Líder do Grupo de Pesquisa do CNPq Comunicação e Saúde, coordenadora do GP Comunicação, Divulgação Científica, Saúde e Meio Ambiente da Intercom e Editora Associada da Revista Interface. Email: katia.lerner@icict.fiocruz.br..

${ }^{2}$ Isaltina Gomes é Professora Titular da Universidade Federal de Pernambuco (UFPE), onde atua como docente no curso de Jornalismo, do Departamento de Comunicação Social, e no Programa de PósGraduação em Comunicação. Fez Mestrado e Doutorado em Linguística, ambos na UFPE. Trabalha com questões relacionadas à linguagem nos meios de comunicação, mas tem interesse especial pela área de Divulgação Científica, na qual desenvolve trabalhos acadêmicos e profissionais desde 1999. É líder do Grupo de Pesquisa do CNPq Comunicação e Discurso e pesquisadora PQ1D do CNPq. Foi membro do Comitê Assessor de Divulgação Científica do CNPq (2011-2017). Vice-Presidente da Associação Nacional de Programas de Pós-Graduação de Comunicação (Compós) no período 2017-2019. Email: isaltina@gmail.com.
} 
processo teve como um de seus pilares uma nova forma de conceber as relações entre saúde, doença e corpo: a lógica do risco. A concepção moderna da doença que a caracterizava como lesão a ser localizada pelos sintomas e passível de intervenção pelas tecnologias médicas foi reconfigurada com a descoberta dos fatores de risco nos anos 1950's. Aqui, um novo deslocamento se produziu, pois a doença, antes mesmo de se configurar enquanto tal, já passava a ser concebida na sua forma virtual. Fatores como predisposição genética e estilos de vida (tabagismo, sedentarismo, alimentação) se tornaram elementos preponderantes na antecipação do "estar doente", e faziam parte de um sistema de crenças que apostava na ação humana como forma de se evitar o adoecimento, com a intensa vigilância e intervenção sobre os corpos e a culpabilização do ser humano pelo seu próprio adoecimento.

A saúde foi adquirindo centralidade a partir dos anos 1970's, tornando-se foco de preocupação de diversos grupos sociais, em especial nas camadas médias urbanas. No Brasil, observamos nos anos 1980's a chamada "Geração Saúde", que promoveu hábitos ditos saudáveis, na perseguição ao ideal da saúde perfeita que paulatinamente passava a se constituir num imperativo e numa nova moralidade. Este cenário envolveu o surgimento de novos discursos, sujeitos e saberes, e estava relacionado a um complexo industrial cada vez mais poderoso que até hoje movimenta e é movimentado pelo ideário da saúde como utopia nas sociedades capitalistas contemporâneas.

Os temas de saúde e doença, que desde cedo se constituíram objeto de políticas públicas e estiveram presentes em hospitais e consultórios médicos no século XX, ultrapassaram esses espaços para figurar regularmente na vida cotidiana. Para tal, o novo cenário comunicacional que se consolida no século XX tem uma importância crucial, em especial com a expansão da indústria cultural. Notícias, reportagens, novelas, filmes e publicidade pouco a pouco disseminaram a relevância do cuidado com a saúde, tornando mais familiar um universo até então distante. No entanto, os meios massivos não devem ser vistos, apenas, como espaços de reverberação de um processo em curso. Trata-se da emergência da mídia como ator importante na constituição da saúde como questão pública. No jornalismo, em especial, observa-se a orquestração particular de certas falas que acabava por atribuir sentidos, visibilidade e legitimidade a determinados temas e atores. Cabe, ainda, destacar como certos eventos sanitários nasceram já sob escrutínio público e tiveram sentidos 
construídos para além da jurisdição médico-científica, na e por meio da mídia, como se observa, por exemplo, no caso das epidemias de Aids (1980's) e Zika (2010's).

O desenvolvimento das tecnologias de comunicação e informação (TIC's), em especial com o advento da internet e dos dispositivos móveis, trouxe uma ambiência comunicacional marcada por novas lógicas e racionalidades, com o deslocamento da centralidade dos meios na organização dos processos interacionais entre os campos sociais. No contexto da midiatização emergem novas práticas, formas de sociabilidade e processos de subjetivação que também irão impactar os fenômenos associados à saúde, estabelecendo renovadas articulações entre esses campos. É em diálogo com esse cenário que podemos ler o conjunto de textos aqui reunidos. O primeiro deles, A saúde como autorrealização: o imaginário na fanpage 'Melhor com Saúde', traz uma reflexão sobre as formas de se viver a saúde em uma sociedade hiperconectada, marcada pela cultura terapêutica e pelo hedonismo. Nela, a saúde passa a ser entendida como utopia de felicidade individual e autorrealização, em um empreendimento que visa o eficaz gerenciamento de si.

$\mathrm{O}$ artigo $\mathrm{O}$ impacto do diagnóstico de esclerose múltipla e as narrativas de testemunhos das novas vidas possíveis também aborda os processos de subjetivação relacionados à experiência da saúde/doença. Aqui, o testemunho ocupa um lugar central, e sua disseminação na nova ambiência digital possibilita a ampla visibilidade de uma experiência traumática, contribuindo para a construção de novas identidades organizadas em torno da doença. Esse lugar de sujeito envolve, ainda, a ressignificação da enfermidade como experiência positiva, oportunidade de aprimoramento pessoal, conferindo um novo sentido à vida. Já em $\mathbf{O}$ café é o novo ovo? Publicização jornalística das notícias que relacionam café e saúde temos o debate sobre a produção de sentidos atribuídos ao café nos discursos midiáticos a partir de notícias que relacionam o seu consumo ao ideal de vida saudável e produtiva, num contexto de gourmetização de alimentos. Os autores enfatizam como as práticas de consumo estão articuladas à construção de biossociabilidades e vinculam-se à gestão de si voltada para produtividade e performance.

A partir de um corpus constituído por revistas e sites de boa forma e dietas, o texto Grávida perfeita: efeitos do discurso midiático da boa forma voltado para gestantes discute como o discurso midiático faz circular efeitos de sentidos que acabam por ditar que a mulher grávida deve buscar um ideal de corpo no qual as marcas da gestação devem ser o 
quanto antes apagadas. Não basta ser mãe, é preciso ser "magra, linda e sexy", apontando o valor da autodisciplina e do corpo como prova material de uma vida de sucesso. No embate entre o corpo real e aquele difundido pela mídia, esta desponta enquanto matriz criadora de valores simbólicos, estéticos e sociais, associada à necessidade econômica dos mercados. Na sequência, Clínica, mídia e consumo: das medialidades do Transtorno de Estresse PósTraumático se propõe a realizar uma genealogia da categoria trauma enquanto entidade nosológica, articulando sua emergência às transformações das sociedades contemporâneas e à experiência de consumo. $\mathrm{O}$ autor identifica a progressiva hipertrofia do repertório psiquiátrico nos modos de subjetivação contemporâneos, que se situam em um contexto marcado por uma modalidade de consumo experiencial, o que se afina com as novas técnicas terapêuticas propostas para lidar com o trauma da guerra, que utilizam tecnologias de simulação.

As articulações entre tecnologia e saúde também estão presentes em Youtubers falam de saúde jogando: análise de vídeos produzidos por brasileiros. Entendendo os jogos digitais como mídias capazes de produzir representações do mundo, os autores analisam youtubers jogando e comentando seus jogos. Apontam o entrelaçamento de sentidos produzidos no mundo físico com aqueles dos mundos ficcionais, tanto na observação das regras e procedimentos como pelos enunciados dos jogadores em ação. Como resultados preliminares, afirmam que os sentidos vocalizados sobre consumo de bebidas alcóolicas, cigarros e drogas ilícitas trazem as oposições saudável e não-saudável, bem e mal, reproduzindo as classificações morais das sociedades contemporâneas e dos sentidos circulantes sobre saúde. No texto seguinte, Práticas integrativas e complementares em saúde: análises sobre a produção discursiva na mídia, são analisadas revistas de grande circulação no país para verificar seu discurso sobre práticas alternativas de cuidado. O texto aponta que, a despeito de certa abertura no campo biomédico para a adoção destas práticas, os enunciados reproduzem as tradicionais hierarquias da saúde, ao localizar nos especialistas (em especial médicos e instituições hospitalares) os sujeitos autorizados a recomendar a sua utilização; aponta, ainda, a lógica neoliberal como uma das forças que fundamentam a aceitação dessas práticas, com o reconhecimento nas revistas de sua rentabilidade econômica.

Em tempos de boatos e notícias falsas, a saúde pública também é atingida. Saúde Sem Fake News: estudo e caracterização das informações falsas divulgadas no canal de 
informação e checagem de fake news do Ministério da Saúde procura identificar as principais características deste tipo de notícias em um canal de informações do Ministério da Saúde. Com a maior circulação de discursos concorrentes aos oficiais, possibilitada pelas TIC's, chama a atenção a quantidade de notícias contra vacinação. Temas diversos apareceram, como curas, receitas milagrosas, alimentos poderosos e outras propostas de solução aos problemas cotidianos dos cidadãos. Já Deu Zika na rede: Uma análise sobre a produção de sentidos sobre a epidemia de zika e microcefalia no Facebook foca os boatos que marcaram a epidemia do vírus da Zika e da microcefalia, tomando como base os comentários de posts das páginas no Facebook de dois importantes jornais. O estudo identificou que o ambiente de incerteza e o desconhecimento científico podem ter sido alguns dos fatores que levaram à estimulação dos boatos, concluindo que o enfraquecimento do estatuto de verdade da ciência e da própria verdade fluida participa do protagonismo do boato na atualidade midiatizada.

Por fim, um último conjunto de textos aponta para as renovadas relações entre mídia, saúde e Estado. O artigo Discurso e hegemonia no jornal Tribuna do Norte: a gestão privada de serviços públicos e a construção de sentidos sobre as Organizações Sociais (Oss) busca analisar a produção de sentidos na grande imprensa de Natal sobre a gestão privada das OSs nos serviços públicos de saúde. Os autores evidenciam que a cobertura noticiosa reforça a ideia de ineficiência estatal e a necessidade de abertura ao setor privado. Essa perspectiva neoliberal, comum em grande parte das revistas e jornais comerciais brasileiros, tem como contraponto os sentidos propostos por um periódico produzido em uma instituição pública de saúde, a Fiocruz. Ao investigar como a saúde é rememorada pela revista Radis, o texto Saúde e Memória nas páginas da Radis: o passado se faz presente evidencia o acionamento de um passado silenciado, o do processo de construção da Reforma Sanitária, sinalizando que a revista assume o lugar de guardiã desta memória. Ao falar sobre este passado, constrói sua identidade e reforça uma posição de luta pela saúde pública na disputa discursiva sobre o Sistema Único de Saúde. E, fechando o dossiê, The media and HIV/AIDS education campaigns: Corporate Responsibility, aesthetics and power, analisa as campanhas educativas sobre HIV/Aids, e aponta o enfraquecimento da antiga aliança entre governos, mídia e instituições internacionais, em contraposição ao crescente protagonismo de corporações, como a MTV. A força da marca nas campanhas afeta os modos como os 


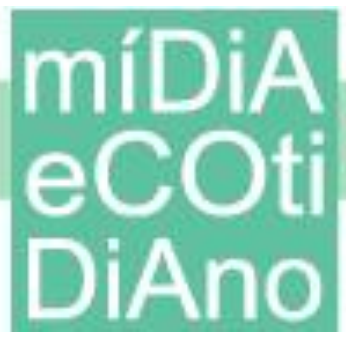

sentidos são produzidos e consumidos, em especial pela preponderância da perspectiva neoliberal, que enfatiza as noções de desejo e emoção, a responsabilidade individual e a estetização das mensagens. Esperamos que os textos possam contribuir para o adensamento das reflexões sobre as relações entre mídia e saúde.

Em seguida, esta edição apresenta mais seis textos em sua seção livre. O primeiro é um texto da pesquisadora Leda Mansour sobre a prática da "re-informação online", que contempla a esfera de re-informação da web francesa e, mais especificamente, centenas de sites e blogs em conexão com ideias da ultra direita. A autora destaca que, ao mesmo tempo em que o uso do prefixo "re" em "re-informar" carrega uma ideia de renovação e revisão crítica, ele é utilizado por sites de re-informação para demarcar uma contra-informação, uma negação ou rejeição de uma outra informação. Além disso, a seção livre contempla temas que incluem a reflexão sobre as relações entre memória e esquecimento no cotidiano hipermidiático, observando a desvalorização histórica do esquecimento, utilizando trechos do curta Toda a memória do mundo (1956), de Alain Resnais, e abordando o fenômeno do Big data (artigo de Nicholas Andueza e Carlos Affonso Mello); uma análise do caráter simbólico nas redes sociais com a interação dos influenciadores digitais feita através de um estudo de caso da influenciadora digital maranhense Thaynara OG no Instagram (artigo de Bruna Maria Paixão Castelo Branco, José Ferreira Júnior e Karla Silva Almeida); um estudo sobre o fetiche exercido pelos produtos saudáveis em programas de TV sobre saúde, com uma pesquisa realizada entre pessoas que assistem e não assistem ao programa Bem Estar, da Rede Globo (artigo de Jeferson Bertolini); uma investigação sobre como as pessoas se relacionam com espaços de luto e silêncio por meio de selfies e o auxílio da hashtag \#Holocaustmonument (artigo de Thiago Costa e Maria Teresa Ferreira Bastos) e, por último, uma discussão do conceito de Movimento Social e de Movimento Grassroot aplicado à Marcha das Mulheres, que também traz uma análise documental da comunicação digital desse movimento, focando nos esforços de comunicação feitos por um grupo localizado em Mount Desert Island, no estado do Maine (artigo em inglês de Nívea Canalli Bona).

Tenham uma ótima leitura!

Katia Lerner e Isaltina Gomes (Editoras da Seção Temática)

Andrea Medrado e Denise Tavares (Editoras da Seção Livre) 